\title{
Phenolic-Rich Baccaurea angulata Modulates Inflammatory Biomarkers of Atherosclerosis
}

\author{
Muhammad Ibrahim ${ }^{(D},{ }^{1}$ Maryam Abimbola Mikail ${ }^{(D},{ }^{2}$ Idris Adewale Ahmed, ${ }^{3}$ \\ and Radiah Abdul Ghani ${ }^{1}$ \\ ${ }^{1}$ Kulliyyah of Allied Health Sciences, International Islamic University Malaysia, Kuantan Campus, Kuantan, Malaysia \\ ${ }^{2}$ Department of Biomedical Science, Faculty of Science, Lincoln University College, Petaling Jaya, Malaysia \\ ${ }^{3}$ Department of Biotechnology, Faculty of Science, Lincoln University College, Petaling Jaya, Malaysia
}

Correspondence should be addressed to Muhammad Ibrahim; abumaisarah@iium.edu.my and Maryam Abimbola Mikail; maryamabimbola@lincoln.edu.my

Received 17 July 2018; Accepted 18 September 2018; Published 5 November 2018

Academic Editor: Phillip B. Hylemon

Copyright (C) 2018 Muhammad Ibrahim et al. This is an open access article distributed under the Creative Commons Attribution License, which permits unrestricted use, distribution, and reproduction in any medium, provided the original work is properly cited.

\begin{abstract}
Purpose. Cardiovascular disease (CVD) is the leading and the most critical type of chronic disease. Atherosclerosis is the most common cause of CVD. Inflammation has been progressively acknowledged as a vital and central player in the pathophysiology of atherosclerosis. Baccaurea angulata is an underutilized fruit of the island of Borneo. It was obtained from Bau, Sarawak, Malaysia. In our previous studies, $B$. angulata did not only increase antioxidant enzyme activities, but also slowed the lipid peroxidation process in high-cholesterol-fed rabbits. It was hypothesized that $B$. angulata fruit would exert an anti-inflammatory effect. This study, therefore, aimed at evaluating and comparing the effects of three different B. angulata whole fruit (WF) juice doses on 11 serum inflammatory biomarkers of atherosclerosis. Methods. Thirty-five male New Zealand white rabbits were divided into seven groups $(n=5)$. Group $\mathrm{CH}$ was fed $1 \%$ cholesterol diet only, group $\mathrm{C} 1$ was fed $1 \%$ cholesterol diet and $0.5 \mathrm{ml} / \mathrm{kg} / \mathrm{day} B$. angulata WF juice, group C2 was fed $1 \%$ cholesterol diet and $1.0 \mathrm{ml} / \mathrm{kg} / \mathrm{day}$ B. angulata WF juice, group C3 was fed $1 \%$ cholesterol diet and $1.5 \mathrm{ml} / \mathrm{kg}$ /day B. angulata WF juice, group N was fed standard pellet only, group N1 was fed standard pellet and $0.5 \mathrm{ml} / \mathrm{kg} /$ day B. angulata WF juice, and group $\mathrm{N} 2$ was fed standard pellet and $1.0 \mathrm{ml} / \mathrm{kg} / \mathrm{day}$ B. angulata WF juice for 12 weeks. Results. The administration of the various juices reduced the concentrations of induced serum inflammatory biomarkers. Conclusion. This protective effect of $B$. angulata fruit against cardiovascular risk might be due to its polyphenol content.
\end{abstract}

\section{Introduction}

Atherosclerosis, a systematic disease that manifests in the coronary circulation, has traditionally been highly correlated with dyslipidemia. When fats and lipids build up in and on the walls of large arteries, they restrict blood flow, resulting in thrombotic occlusion of the affected vessel [1]. Chronically expanding atherosclerotic lesions can lead to complete artery lumen occlusion and pose serious cardiovascular complications [2]. Fat accumulations in the arterial wall and hyperlipidemia have accordingly been the therapeutic targets in the prevention and treatment of atherosclerosis.
Cholesterol-lowering drugs and a cholesterol-restricted diet are both common constituents of an antiatherosclerotic regimen [3].

Atherosclerosis begins when the inner cellular lining of the circulatory system, called the endothelium, becomes damaged in response to endothelial nitric oxide synthase (eNOS) dysfunction, monocyte attraction, activation of coagulation, and complement systems as well as increase in vascular permeability [4]. Low-density lipoprotein (LDL) crosses the damaged endothelium into the wall of the artery. Low-density lipoprotein builds up in enormous amounts and gets trapped within the arterial intima. This causes the 
white blood cells to leave the bloodstream and infiltrate the arterial walls to digest the LDL. Over many years, the toxic mess of cholesterol, white blood cells, and inflammatory cytokines combine to form plaque in the arterial wall [5]. Atherosclerosis is now widely accepted as an inflammatory disease involving chronic inflammation driven by immune responses to lipid deposition in the arterial wall. In addition to the accumulation of fat in the arterial walls, infiltrating macrophages, lymphocytes, and other inflammatory and immune cells that occur at such locations also significantly contribute to the pathology of this disease [6].

It is worthwhile mentioning that an inflammation is part of the complex biological process in which the vascular system helps fight harmful stimuli. At low levels (acute), inflammation is a lifesaver and acts as a protective attempt. Soon after any injurious stimuli, white blood cells move with urgent haste to the scene of infection to fight off the intruders and repair the damage [7]. However, there is a quiet, yet destructive, kind of inflammation that can seriously undermine the health: chronic inflammation-a silent trouble that does not only persist for a long time but also contributes to a host of other diseases such as atherosclerosis, if left unchecked [8]. Dietary factors as anti-inflammatory agents, however, are able to maintain health as well as reverse the progression of chronic diseases [9]. Therefore, current research efforts are focusing on inflammation as a new intervention strategy for the treatment of atherosclerosis. Several lines of evidence have supported the idea that circulating biomarkers of inflammation can be affected by diet composition [10].

Antioxidants play a favorable role on several mechanisms involved in combating atherosclerosis. Antioxidants are electron donors and thus prevent oxidation of LDL, one of the key events associated with atherosclerosis [10]. Antioxidants act as anti-inflammatory agents by interfering with inflammatory gene expression [11].

The results of earlier studies demonstrated the antioxidant properties of Baccaurea angulata fruit juice through the inhibition of LDL oxidation and enhancement of enzymatic antioxidants [12-17]. Furthermore, the beneficial effects of antioxidants on inflammation have been greatly reported. It was, therefore, hypothesized that $B$. angulata fruit would exert an anti-inflammatory effect. To explore this hypothesis, this present study aimed at evaluating and comparing the effects of three different doses of $B$. angulata whole fruit (WF) juice administered at $0.5,1.0$, and $1.5 \mathrm{ml} / \mathrm{kg} /$ day on 11 serum inflammatory biomarkers (cytokines) of atherosclerosis such as interleukin-1 (IL-1), interleukin-2 (IL-2), interleukin-6 (IL-6), interleukin-7 (IL-7), interleukin-8 (IL-8), interleukin-18 (IL-18), intercellular cell adhesion molecule-1 (ICAM-1), vascular cell adhesion molecule-1 (VCAM-1), C-reactive protein (CRP), tumor necrosis factor- $\alpha$ (TNF- $\alpha$ ), and P-selectin in rabbits fed high-cholesterol diet. Baccaurea is a genus of flowering plant belonging to the family Phyllanthaceae. The genus comprises over 100 species, one of which is Baccaurea angulata. In English, the exotic fruit is usually called red angel starfruit, because of its resemblance with the starfruit (Averrhoa carambola). This fruit, however, is grown and very popular in the island of
Borneo. It was obtained from Bau, Sarawak, Malaysia, and is locally called "Belimbing Dayak."

\section{Materials and Methods}

2.1. Assay Kits. Rabbit interleukins (IL-1, IL-2, IL-6, IL-7, IL8, and IL-18), ICAM-1, VCAM-1, CRP, TNF- $\alpha$, and $\mathrm{P}$-selectin kits were purchased from Cusabio (China).

2.2. Plant Materials. Fresh and fully matured B. angulata fruits were obtained from Bau, Sarawak, Malaysia. The fruits were morphologically identified and authenticated by an expert at the Forest Research Institute Malaysia (FRIM) and stored at $-30^{\circ} \mathrm{C}$.

2.3. Juice Preparation. The fruits without any physical damage were selected every day for juice preparation. The fruits were washed thoroughly with distilled water and then juiced with an electric fruit juicer exactly before consumption. The red skinned fruit has pinkish arils with a tangy taste and a sweet-tart flavour.

2.4. Cholesterol Diet Preparation. A 1\% cholesterol diet was prepared by adding $40 \mathrm{~g}$ of analytical-grade pure cholesterol powder to each $3960 \mathrm{~g}$ of rabbit chow pellet (Bengy, Malaysia) (1\% cholesterol, w/w, in food pellet). Cholesterol powder was first dissolved in $1600 \mathrm{ml}$ of $99.9 \%$ chloroform and then mixed with rabbit chow pellets in a fume hood. After thorough mixing, the diet was transferred into a hot air oven, maintained at $37^{\circ} \mathrm{C}$ for chloroform evaporation. After about two days, cholesterol diet was stored in a chiller $\left(2-8^{\circ} \mathrm{C}\right)$.

2.5. Animals and Study Design. Thirty-five male New Zealand white rabbits (Sapphire Enterprise, Seri Kembangan, Selangor, Malaysia) varying in weight from $2.45 \pm 0.23$ to $2.81 \pm 0.27 \mathrm{~kg}$ on arrival were randomly housed in a controlled environment, maintained at $20 \pm 11^{\circ} \mathrm{C}, 55 \pm 5 \%$ humidity and 12-hour light/dark cycles. The rabbits were fed standard rabbit pellets and water ad libitum for 2 weeks to acclimatize. Following acclimatization, rabbits were then divided into seven groups of five rabbits each $(n=5)$. Group $\mathrm{CH}$ was fed $1 \%$ cholesterol diet only, group $\mathrm{C} 1$ was fed $1 \%$ cholesterol diet and $0.5 \mathrm{ml} / \mathrm{kg} /$ day $B$. angulata WF juice, group C2 was fed $1 \%$ cholesterol diet and $1.0 \mathrm{ml} / \mathrm{kg} /$ day $B$. angulata WF juice, group C3 was fed $1 \%$ cholesterol diet and $1.5 \mathrm{ml} / \mathrm{kg} /$ day $B$. angulata WF juice, group $\mathrm{N}$ was fed standard pellet only, group N1 was fed standard pellet and $0.5 \mathrm{ml} / \mathrm{kg} /$ day B. angulata WF juice, and group $\mathrm{N} 2$ was fed standard pellet and $1.0 \mathrm{ml} / \mathrm{kg} /$ day $B$. angulata WF juice for 12 weeks. The foods (cholesterol diet and standard pellet) were restricted to $120 \mathrm{~g}$. The dosage forms of $B$. angulata were administered to rabbits orally by sterile gavage. Fresh and clean water was provided either by open dish or nipple drinker. All experimental protocols were approved by the animal care and use committee of the Faculty of Medicine, 
International Islamic University Malaysia (IIUM) Kuantan Campus, Pahang (ID NO. IREC 05; Meeting No. 4/2012).

2.6. Blood Sampling and Analysis. Blood from rabbits that were deprived of food overnight [18] was obtained at week 0 and the end of the experiment (week 12). Blood samples were collected from the marginal ear vein. After centrifugation at $1800 \mathrm{~g}$ and $4^{\circ} \mathrm{C}$ for 15 minutes, serum was aliquoted and stored at $-80^{\circ} \mathrm{C}$ until use. Each serum sample was assayed for inflammatory biomarkers of atherosclerosis.

2.7. Determination of Inflammatory Cytokines. Serum IL-1, IL-2, IL-6, IL-7, IL-8, and IL-18, ICAM-1, VCAM-1, CRP, TNF- $\alpha$, and P-selectin were evaluated using the Cusabio (Hubei Province, China) ELISA kits. Analyses were done according to the manufacturer's instructions.

2.8. Statistical Analysis. Data were expressed as mean \pm SD $(n=5)$. The data were analyzed by ANOVA using Statistical Package for Social Sciences (SPSS) software (version 20.0, IBM), and the differences between the means were compared by multivariate analysis of variance (MANOVA) with Duncan's multiple range post hoc test. Statistical significance was considered at $p<0.05$.

\section{Results}

The mean serum cytokine levels were obtained at weeks 0 and 12. According to the statistical evaluation, at the beginning of this study (week 0 ), there were no statistical differences in the concentrations of the serum cytokines between the groups of rabbits. Consequently, the mean values of the final results obtained (week 12) are presented in Table 1 for Interleukins-1, 2, 6, 7, 8, and 18 and Table 2 for ICAM-1, VCAM-1, CRP, TNF- $\alpha$, and P-selectin.

\subsection{Effects of B. angulata WF Juice Doses on Serum} Interleukins-1, 2, 6, 7, 8, and 18. Serum IL-1 was significantly $(p<0.05)$ increased in the $\mathrm{CH}$ group. On the contrary, an elevated serum IL-1 level induced by feeding on highcholesterol diet was reduced in the $0.5,1.0$, and $1.5 \mathrm{ml} / \mathrm{kg}$ /day $B$. angulata WF-treated groups (C1, C2, and C3) but with no dose-dependent effect. There was no statistically significant $(p>0.05)$ difference between groups $\mathrm{N}$, $\mathrm{N} 1$, and $\mathrm{N} 2$ after 12 weeks of B. angulata WF administration.

High-cholesterol diet increased serum IL-2 concentrations in the groups $\mathrm{CH}, \mathrm{C} 1, \mathrm{C} 2$, and C3. Statistically significant $(p<0.05)$ higher mean serum IL-2 level was seen in the $\mathrm{CH}$ group relative to the treatment groups $(\mathrm{C} 1, \mathrm{C} 2$, and C3). There was no statistically significant $(p>0.05)$ difference between groups N1 and N2. Group N, however, was significantly $(p<0.05)$ higher than groups N1 and N2.

No significant $(p>0.05)$ difference was found in the concentrations of serum IL-6 of groups $\mathrm{CH}, \mathrm{C} 1, \mathrm{C} 2$, and C3. However, the IL-6 level of both C2 group and C3 group had no significant $(p>0.05)$ difference compared with that of group N. A dose-dependent pattern was found in the serum IL-6 of the C1, C2, and C3 groups. There appeared to be no significant $(p>0.05)$ difference between groups $\mathrm{N}, \mathrm{N} 1$, and N2.

Serum IL-7 level in CH group was remarkably $(p<0.05)$ higher than those of the C1, C2, and C3 groups. Serum IL-7 showed no significant $(p>0.05)$ difference between groups $\mathrm{N}, \mathrm{N} 1$, and N2. Baccaurea angulata WF dose-dependently reduced serum IL-7.

Serum IL- 8 increased after feeding rabbits with highcholesterol diet for 12 weeks. Administering B. angulata WF juice to high-cholesterol-fed rabbits lowered the serum IL-8 level in a dose-dependent manner. The concentrations of serum IL-8 of C1, C2, and C3 groups were significantly $(p<0.05)$ lower than that of the $\mathrm{CH}$ group. Likewise, that of the $\mathrm{N}$ group was significantly $(p<0.05)$ higher than those of the N1 and N2 groups.

High-cholesterol diet resulted in an increase in IL-18, which was ameliorated by treatment with $B$. angulata WF juices, but with no clear-cut dose-dependent pattern. Compared with the $\mathrm{CH}$ group given cholesterol diet only, all doses significantly $(p<0.05)$ decreased IL-18 of groups C1, $\mathrm{C} 2$, and $\mathrm{C} 3$. When comparing group $\mathrm{N}$ with the $\mathrm{N} 1$ and $\mathrm{N} 2$ groups, serum IL-18 levels were not significantly $(p>0.05)$ different between the groups.

3.2. Effects of B. angulata WF Juice Doses on Serum ICAM-1, $V C A M-1, C R P, T N F-\alpha$, and P-Selectin. In contrast to the $\mathrm{CH}$ group, the concentrations of serum ICAM-1 significantly $(p<0.05)$ decreased in the B. angulata WF-treated groups (C1, C2, and C3). Baccaurea angulata WF dose-dependently decreased serum ICAM-1 in cholesterol-fed rabbits. No significant $(p>0.05)$ difference was found in the concentrations of serum ICAM-1 of groups N, N1, and N2.

Although no significant $(p>0.05)$ difference between $\mathrm{CH}, \mathrm{C} 1, \mathrm{C} 2, \mathrm{~N}$, and $\mathrm{N} 1$ groups in serum VCAM-1 was observed, both groups C3 and N2, nevertheless, had a significant $(p<0.05)$ decrease compared with $\mathrm{CH}$ group.

There was no significant $(p>0.05)$ difference between the $\mathrm{CH}, \mathrm{C} 1$, and $\mathrm{C} 2$ groups in their levels of serum CRP. Whereas, $1.5 \mathrm{ml} / \mathrm{kg} /$ day $B$. angulata WF significantly $(p<0.05)$ reduced serum CRP levels in the C3 group compared with $\mathrm{CH}, \mathrm{C} 1$, and $\mathrm{C} 2$ groups. The magnitude of $\mathrm{CRP}$ increase was 9-fold greater in the $\mathrm{CH}$ group rabbits than in $\mathrm{C} 3$ group rabbits. A dose-dependent pattern was found in the serum CRP of the C1, C2, and C3 groups. No significant $(p>0.05)$ difference in CRP levels was observed between $\mathrm{C} 3, \mathrm{~N}, \mathrm{~N} 1$, and $\mathrm{N} 2$ groups.

After 12 weeks of experimental study, high-cholesterol diet increased serum TNF- $\alpha$ concentrations in the groups $\mathrm{CH}, \mathrm{C} 1, \mathrm{C} 2$, and $\mathrm{C} 3$. However, compared with groups $\mathrm{C} 1$, $\mathrm{C} 2$, and $\mathrm{C} 3$, the serum TNF- $\alpha$ level of rabbits in the $\mathrm{CH}$ group increased significantly $(p<0.05)$. The effect of $B$. angulata WF on serum CRP was found to be dosedependent. There was no significant $(p>0.05)$ difference between groups $\mathrm{N}, \mathrm{N} 1$, and $\mathrm{N} 2$.

The level of serum $\mathrm{P}$-selectin in the $\mathrm{CH}$ group after 12week feeding was raised significantly $(p<0.05)$ compared with $\mathrm{C} 1, \mathrm{C} 2$, and C3 groups. No significant $(p>0.05)$ difference was found in the concentrations of serum P-selectin 
TABLE 1: Effects of B. angulata WF juice doses on serum Interleukins-1, 2, 6, 7, 8, and 18.

\begin{tabular}{|c|c|c|c|c|c|c|}
\hline Groups & IL-1 (pg/ml) & IL-2 (pg/ml) & IL-6 (pg/ml) & IL-7 (pg/ml) & IL-8 (pg/ml) & IL-18 (pg/ml) \\
\hline $\mathrm{CH}$ & $72.33 \pm 6.17^{\mathrm{a}}$ & $228.92 \pm 11.10^{\mathrm{a}}$ & $127.27 \pm 10.12^{\mathrm{a}}$ & $10.43 \pm 1.14^{\mathrm{a}}$ & $191.62 \pm 13.56^{\mathrm{a}}$ & $79.36 \pm 7.30^{\mathrm{a}}$ \\
\hline $\mathrm{C} 1$ & $47.94 \pm 2.82^{\mathrm{b}, \mathrm{c}}$ & $123.01 \pm 10.02^{\mathrm{b}}$ & $120.63 \pm 7.64^{\mathrm{a}}$ & $2.48 \pm 0.11^{\mathrm{b}}$ & $165.63 \pm 10.04^{b}$ & $8.62 \pm 1.17^{\mathrm{c}}$ \\
\hline $\mathrm{C} 2$ & $57.75 \pm 4.63^{b}$ & $137.19 \pm 7.04^{\mathrm{b}}$ & $98.65 \pm 7.21^{\mathrm{a}, \mathrm{b}}$ & $1.98 \pm 0.56^{\mathrm{b}}$ & $145.83 \pm 9.00^{c}$ & $15.18 \pm 3.97^{\mathrm{c}}$ \\
\hline $\mathrm{C} 3$ & $39.77 \pm 2.53^{c}$ & $102.72 \pm 9.39^{\mathrm{b}}$ & $95.58 \pm 6.56^{\mathrm{a}, \mathrm{b}}$ & $1.72 \pm 0.32^{\mathrm{b}}$ & $53.47 \pm 9.73^{\mathrm{e}}$ & $27.58 \pm 4.09^{\mathrm{b}}$ \\
\hline $\mathrm{N}$ & $37.31 \pm 5.87^{c}$ & $205.86 \pm 11.37^{\mathrm{a}}$ & $86.60 \pm 8.15^{\mathrm{b}, \mathrm{c}}$ & $1.57 \pm 0.27^{\mathrm{b}}$ & $78.67 \pm 7.12^{\mathrm{d}}$ & $15.78 \pm 2.02^{c}$ \\
\hline N1 & $43.74 \pm 4.29^{\mathrm{b}, \mathrm{c}}$ & $119.78 \pm 7.37^{\mathrm{b}}$ & $77.68 \pm 11.50^{\mathrm{c}}$ & $2.44 \pm 0.09^{\mathrm{b}}$ & $55.17 \pm 8.00^{\mathrm{e}}$ & $14.25 \pm 2.16^{\mathrm{C}}$ \\
\hline $\mathrm{N} 2$ & $38.09 \pm 5.03^{c}$ & $103.33 \pm 9.12^{\mathrm{b}}$ & $70.27 \pm 6.54^{\mathrm{c}}$ & $1.96 \pm 0.56^{\mathrm{b}}$ & $53.15 \pm 8.95^{\mathrm{e}}$ & $13.90 \pm 2.29^{c}$ \\
\hline
\end{tabular}

Values are given as mean $\pm \mathrm{SD}(n=5)$. ${ }^{\mathrm{a}, \mathrm{b}, \mathrm{c}, \mathrm{d}, \mathrm{e}}$ Values not sharing a common superscript letter within the same column differ significantly at $p<0.05$. CH: $1 \%$ cholesterol diet; $\mathrm{C} 1: 1 \%$ cholesterol diet and $0.5 \mathrm{ml} / \mathrm{kg} /$ day $B$. angulata WF juice; C2: $1 \%$ cholesterol diet and $1.0 \mathrm{ml} / \mathrm{kg} /$ day $B$. angulata WF juice; C3: $1 \%$ cholesterol diet and $1.5 \mathrm{ml} / \mathrm{kg} /$ day B. angulata WF juice; N: standard pellet; $\mathrm{N} 1$ : standard pellet and $0.5 \mathrm{ml} / \mathrm{kg} /$ day $B$. angulata WF juice; N2: standard pellet and $1.0 \mathrm{ml} / \mathrm{kg} /$ day $B$. angulata WF juice; IL: interleukin.

TABLE 2: Effects of B. angulata WF juice doses on serum ICAM-1, VCAM-1, CRP, TNF- $\alpha$, and P-selectin.

\begin{tabular}{lccccc}
\hline Groups & ICAM-1 $(\mathrm{ng} / \mathrm{ml})$ & VCAM-1 $(\mathrm{pg} / \mathrm{ml})$ & CRP $(\mathrm{pg} / \mathrm{ml})$ & TNF- $\alpha(\mathrm{pg} / \mathrm{ml})$ & P-selectin $(\mathrm{pg} / \mathrm{ml})$ \\
\hline $\mathrm{CH}$ & $21.49 \pm 4.07^{\mathrm{a}}$ & $352.83 \pm 16.98^{\mathrm{a}}$ & $47.48 \pm 5.16^{\mathrm{a}}$ & $123.71 \pm 13.06^{\mathrm{a}}$ & $30.36 \pm 2.40^{\mathrm{a}}$ \\
$\mathrm{C} 1$ & $7.88 \pm 0.96^{\mathrm{b}}$ & $308.49 \pm 11.79^{\mathrm{a}, \mathrm{b}}$ & $44.42 \pm 6.99^{\mathrm{a}}$ & $37.16 \pm 4.11^{\mathrm{b}}$ & $15.05 \pm 1.73^{\mathrm{b}}$ \\
$\mathrm{C} 2$ & $4.56 \pm 0.68^{\mathrm{c}}$ & $337.67 \pm 11.95^{\mathrm{a}, \mathrm{b}}$ & $36.78 \pm 4.78^{\mathrm{a}}$ & $27.76 \pm 3.89^{\mathrm{b}}$ & $15.50 \pm 3.21^{\mathrm{b}}$ \\
$\mathrm{C} 3$ & $2.78 \pm 0.16^{\mathrm{c}, \mathrm{d}}$ & $173.82 \pm 9.83^{\mathrm{b}}$ & $5.75 \pm 1.56^{\mathrm{b}}$ & $13.64 \pm 2.19^{\mathrm{b}}$ & $12.43 \pm 2.45^{\mathrm{b}}$ \\
$\mathrm{N}$ & $1.08 \pm 0.26^{\mathrm{d}}$ & $278 \pm 12.22^{\mathrm{a}, \mathrm{b}}$ & $14.45 \pm 3.64^{\mathrm{b}}$ & $6.45 \pm 0.47^{\mathrm{c}}$ & $14.30 \pm 1.05^{\mathrm{b}}$ \\
$\mathrm{N} 1$ & $0.93 \pm 0.20^{\mathrm{d}}$ & $265.76 \pm 10.54^{\mathrm{a}, \mathrm{b}}$ & $5.96 \pm 1.38^{\mathrm{b}}$ & $7.38 \pm 1.46^{\mathrm{c}}$ & $8.90 \pm 0.73^{\mathrm{c}}$ \\
$\mathrm{N} 2$ & $0.95 \pm 0.18^{\mathrm{d}}$ & $198.71 \pm 9.49^{\mathrm{b}}$ & $6.38 \pm 0.73^{\mathrm{b}}$ & $6.68 \pm 0.23^{\mathrm{c}}$ & $7.57 \pm 0.75^{\mathrm{c}}$ \\
\hline
\end{tabular}

Values are given as mean $\pm \mathrm{SD}(n=5) .{ }^{\mathrm{a}, \mathrm{b}, \mathrm{c}, \mathrm{d}}$ Values not sharing a common superscript letter within the same column differ significantly at $p<0.05$. CH: $1 \%$ cholesterol diet; $\mathrm{C} 1: 1 \%$ cholesterol diet and $0.5 \mathrm{ml} / \mathrm{kg} /$ day $B$. angulata WF juice; $\mathrm{C} 2: 1 \%$. cholesterol diet and $1.0 \mathrm{ml} / \mathrm{kg} / \mathrm{day} B$. angulata WF juice; C3: $1 \%$ cholesterol diet and $1.5 \mathrm{ml} / \mathrm{kg} /$ day B. angulata WF juice; N: standard pellet; $\mathrm{N} 1$ : standard pellet and $0.5 \mathrm{ml} / \mathrm{kg} /$ day $B$. angulata WF juice; N2: standard pellet and $1.0 \mathrm{ml} / \mathrm{kg} / \mathrm{day}$ B. angulata WF juice; ICAM-1: intercellular cell adhesion molecule-1; VCAM-1: vascular cell adhesion molecule-1; CRP: C-reactive protein; TNF- $\alpha$ : tumor necrosis factor- $\alpha$.

of groups C1, C2, C3, and N after 12 weeks of B. angulata WF administration. Statistically significant $(p<0.05)$ lower mean serum $\mathrm{P}$-selectin levels were seen in N1 and N2 groups relative to group $\mathrm{N}$.

\section{Discussion}

The present study has demonstrated, in line with many recent studies, a link between high-cholesterol diet and inflammatory biomarkers of atherosclerosis. An etiologic role for cholesterol in atherosclerosis, though disputably, has been well established through laboratory and epidemiological studies. Cholesterol, a key causal factor in the genesis of atherosclerosis, has been viewed as one of the most important inducers of inflammatory biomarkers. Male rabbits fed high-cholesterol diet showed a high susceptibility to LDL oxidation and exhibited a significant elevation of high sensitive C-reactive protein (hsCRP), IL-6, and TNF- $\alpha$ in their blood [19]. In a study involving feeding rabbits a diet containing $1 \%$ cholesterol for 5-6 weeks, disturbances in the oxidant-antioxidant balance and an increase of inflammatory markers were reported [18]. The results of our study are consistent with previous observations. Our data showed that feeding rabbits a high-cholesterol diet for 12 weeks caused elevated inflammatory cytokines in serum.

An elevated level of IL-1, a prototypic proinflammatory cytokine, has long been thought to have a key role in the pathophysiology of atherosclerosis. Interleukin-1 causes the endothelial cells to produce more cytokines and adhesion molecules, thus leading to the recruitment of inflammatory cells [20]. We demonstrated that the administration of $B$. angulata WF juices $(0.5,1.0$, and $1.5 \mathrm{ml} / \mathrm{kg} /$ day $)$ exerted a reduction in the serum IL-1 level in high-cholesterol-fed rabbits (Table 1). Therefore, the use of B. angulata WF as a therapeutic plant-based food for the prevention of atherosclerosis progression could be interesting. Several possibilities may explain the wide health benefits of B. angulata WF, including the polyphenol contents which may contribute to its potentially protective role in atherosclerosis. Benn and colleagues [21] reported that diet-induced obese rats that were treated with polyphenol-rich blackcurrant extract showed a lower level of IL-1 than the controls. Likewise, pretreatment with water extract of polyphenolic Ziziphus jujuba fruit (Jujube) suppressed the expression of IL-1 $\beta$ in cultured murine macrophages [22].

Similarly, serum IL-2 levels were also reduced with all doses $(0.5,1.0$, and $1.5 \mathrm{ml} / \mathrm{kg} /$ day) of $B$. angulata WF (Table 1). Interleukin-2, a cytokine produced by activated T-lymphocytes, has long been known as one of the major contributors to atheromatous plaque formation [23]. Given the fact that there is no safe level of drug use and individuals taking oral immunosuppressive medications put themselves at even higher risk for adverse health effects, $B$. angulata WF could be one of the viable options for the prevention of inflammatory process underlying atherosclerosis. Similar to B. angulata WF, a $46 \%$ reduction of stimulated IL-2 was reported in blood after oral intake of medicinal mushroom Agaricus blazei Murill in healthy volunteers [24].

Another interesting finding from this study shows that the elevated serum IL- 6 level induced by feeding 
high-cholesterol diet was dose-dependently reduced in the $B$. angulata WF-treated groups of rabbits (Table 1 ). In a study by Jung and colleagues [25], the mRNA level of IL-6 was downregulated by pressure extract of ginseng. Thus, the present study is important for its contribution to data available on health benefits of underutilized fruits. Many researchers have studied the in-depth nutrition facts and possible use of many well-known fruits, including their effects on cardiovascular health. However, very few underutilized fruits have been scientifically studied. These versatile health benefits exerted by $B$. angulata WF may be partly due to the fact that phenolic compounds which act as excellent antioxidants indirectly contribute to anti-inflammatory action. Baccaurea angulata WF that possessed the potential to minimize the generation of free radicals and displayed high antioxidant properties and protective effect against lipid peroxidation, a promoter of the atherosclerotic event [16], also interferes with the inflammatory stage of atherosclerosis. Our results are in accordance with a previous experimental study which showed that polyphenol-rich Euterpe oleracea Martius (Arecaceae), commonly known as açaí, possessed both antioxidant and anti-inflammatory properties through the reduction of lipid peroxidation, boosting of antioxidant enzymes, and inhibition of proinflammatory cytokine production $[26,27]$.

Moreover, oral administration of $B$. angulata WF juices ( 0.5 , 1.0 , and $1.5 \mathrm{ml} / \mathrm{kg} /$ day) dose-dependently reduced experimentally induced master regulator of T-cell development, IL-7 (Table 1). It has been shown that IL-7 induces inflammation in the endothelium and recruits monocytes/macrophages to the endothelium, thus playing a critical role in atherogenesis [28]. In our present study, B. angulata WF appeared to be effective in reducing this protagonist of atherosclerosis.

In addition, in the scientific literature, there are enough facts to support beyond any doubt the involvement of IL- 8 in the recruitment of inflammatory cells into atherosclerotic plaques [29]. An experimental study [30] has found that an aqueous extract of the fruit of Crataegus pinnatifida var. major decreased the concentration of IL-8 in atherosclerotic rats fed a high-fat diet. This present study with an underutilized fruit, to our knowledge, is the first to report a reduction in IL-8 (Table 1), which plays a crucial role in leukocyte trafficking and activation, in high-cholesterol-fed rabbits [29]. Administering $B$. angulata WF juices to highcholesterol-fed rabbits lowered the serum IL-8 level in a dose-dependent manner. Interleukin-8 represents one of the key enhancers of the inflammatory microenvironment of the insulted vascular wall [29]. Thus, the present study justifies the use of $B$. angulata WF in the traditional system of medicine for the prevention and treatment of atherosclerotic inflammatory response.

Furthermore, IL-18 has also been linked to atherosclerotic events, owing to its expression by macrophages in human plaque and relation to plaque instability [31]. The importance of this cytokine as proatherogenic in mice models of inflammation has been demonstrated by Elhage and colleagues [32]. The authors reported reduced atherosclerosis, in spite of increased serum cholesterol, in IL-18 deficient apoE(-/-) mice. In this study, we observed that the elevated levels of serum IL-18 induced by high-cholesterol feeding were ameliorated (Table 1) after treatment with $B$. angulata WF juices $(0.5,1.0$, and $1.5 \mathrm{ml} / \mathrm{kg} /$ day). The decrease in IL-18 expression which is in agreement with another study [30] suggests that $B$. angulata WF may be a promising option for the treatment and prevention of atherosclerotic vascular disease.

In addition, ICAM-1 is the major adhesion molecule in the development of atherosclerosis. Intercellular cell adhesion molecule-1 plays an important role in the recruitment of leukocytes to sites of atherosclerotic lesions [33]. Involvement of ICAM-1 in the progression of atherosclerosis in the ApoE-deficient mice model has been previously reported [34]. Our data also showed that the 12-week treatment with $B$. angulata WF exerted a distinct antiinflammatory effect as demonstrated by reduced serum ICAM-1 levels in B. angulata WF-treated rabbits (groups $\mathrm{C} 1, \mathrm{C} 2$, and C3) compared with group $\mathrm{CH}$ (Table 2). Baccaurea angulata WF dose-dependently decreased serum ICAM-1 in cholesterol-fed rabbits. This finding is in accordance with a recent study which showed that Piper sarmentosum extract inhibited the expression of ICAM-1 in high-cholesterol-fed rabbits [35].

In addition to exerting an ICAM-1-reducing effect, $B$. angulata WF also effectively reduced another immunoglobulin-like adhesion molecule, the VCAM-1 (Table 2). The molecule that is encoded by the VCAM-1 gene has long been postulated to play a more critical role in the development of atherosclerosis. As previously reported, proinflammatory cytokine levels were increased concurrently with elevated circulating VCAM-1 in atherosclerosis [36]. The exact mechanism of action for B. angulata WF against this family of adhesion molecules (ICAM-1 and VCAM-1) is uncertain, but it is thought that B. angulata WF exerted its adhesion molecule-lowering effect in highcholesterol-fed rabbits perhaps due to inhibition of c-Jun $\mathrm{N}$-terminal kinase (JNK) pathway. The mechanism of this effect is similar to that of adhesion molecule inhibitors, which was originally designed to hinder adhesion molecules' biological activities by inhibiting JNK pathway [37].

Serum level of CRP is a determinant of atherosclerosis severity. C-reactive protein contributes significantly to atherosclerosis owing to its predictive influence for cardiovascular events [38]. In our present study, B. angulata WF caused a reduction of serum CRP levels in the B. angulata WF-treated rabbits (Table 2). Several animal and clinical studies have demonstrated the antiatherosclerotic effects of polyphenol-rich plant products, in part by lowering the CRP level [39]. Therefore, we suggest that B. angulata WF may be useful for the therapeutic treatment of CRP-associated atherosclerosis. Interestingly, it has been suggested that CRP modulates the process of atherosclerosis by inducing endothelial dysfunction and uncoupling endothelial nitric oxide synthase (eNOS) mRNA expression [40]. Thus, B. angulata WF was able to decrease serum levels of induced CRP, which may improve endothelial function. 
Several lines of evidence support the crucial involvement of TNF- $\alpha$ in the pathogenesis of atherosclerosis. A study demonstrated that in apolipoprotein E-deficient $\left(\mathrm{apoE}^{-/-}\right)$ mice, levels of TNF- $\alpha$ expression are closely associated with lesions in atherosclerosis-prone sites [41]. In this study, as compared with group $\mathrm{CH}$, there was a dose-dependent decrease in serum TNF- $\alpha$ levels of $\mathrm{C} 1, \mathrm{C} 2$, and $\mathrm{C} 3$ groups (Table 2).

P-selectins are lectin-like adhesion glycoproteins that function as cell adhesion molecules which mediate leukocyte rolling on the surfaces of activated endothelial cells. The effect and role of P-selectin in the development of atherosclerosis are vital. A $50-75 \%$ reduction in atherosclerotic lesion size has been demonstrated in P-selectin-deficient apolipoprotein E-knockout mice [42]. According to a study, extracts from Ginkgo biloba leaves inhibit the inflammatory process in mice through interfering with the expression of $\mathrm{P}$-selectin [43]. In the present study, B. angulata WF juices ameliorated serum P-selectin levels in groups $\mathrm{C} 1, \mathrm{C} 2$, and C3 as compared with the $\mathrm{CH}$ group (Table 2). Therefore, our study provides evidence that $B$. angulata WF may also reduce progression of atherosclerosis.

Similarly, B. angulata WF appeared to decrease serum cytokines in groups $\mathrm{N} 1$ and $\mathrm{N} 2$ compared with group $\mathrm{N}$. The levels of IL-2, IL-8, and P-selectin in Group N was, however, significantly higher $(p<0.05)$ than those in groups $\mathrm{N} 1$ and N2. Our results confirmed that a properly balanced diet is essential to reduce risk factors for chronic diseases such as CVD. Maximum health benefits could, therefore, be achieved with normocholesterolemic diet and $B$. angulata $\mathrm{WF}$, which is likely due to its phenolic constituents.

\section{Conclusion}

The present study demonstrated that $B$. angulata WF juice had very pronounced anti-inflammatory effects. It lowered the concentrations of serum inflammatory biomarkers of atherosclerosis in high-cholesterol-fed rabbits. Similar lowered serum inflammatory biomarkers were observed in rabbits fed standard pellet (normocholesterolemic groups) and were administered $B$. angulata WF juices. With hypercholesterolemic diet, $1.5 \mathrm{ml} / \mathrm{kg} /$ day $B$. angulata WF juice appeared to be more effective than both 0.5 and $1.0 \mathrm{ml} / \mathrm{kg} /$ day B. angulata WF juices in reducing the cytokines. These results suggest that the anti-inflammatory effects of $B$. angulata WF might be due to its phenolic constituents or might be partly due to its antioxidant properties.

\section{Conflicts of Interest}

The authors declare that they have no conflicts of interest.

\section{Acknowledgments}

The authors are thankful to the Ministry of Science, Technology and Innovation (MOSTI) for funding this project (Project Nos. 06-01-08-SF0111 and 06-01-08-SF0112). The authors are also very grateful to the Integrated Centre for
Research Animal Care and Use (ICRACU) and Kulliyyah of Allied Health Science, IIUM, for financial and technical assistances.

\section{References}

[1] D. A. Chistiakov, V. A. Myasoedova, V. V. Revin, A. N. Orekhov, and Y. V. Bobryshev, "The phenomenon of atherosclerosis reversal and regression: lessons from animal models," Experimental and Molecular Pathology, vol. 102, no. 1, pp. 138-145, 2017.

[2] K. D. Boudoulas, F. Triposkiadis, P. Geleris, and H. Boudoulas, "Coronary atherosclerosis: pathophysiologic basis for diagnosis and management," Progress in Cardiovascular Diseases, vol. 58, no. 6, pp. 676-692, 2016.

[3] M. Patel and C. Kothari, "Critical review of statins: a bioanalytical perspective for therapeutic drug monitoring," $\operatorname{Tr} A C$ Trends in Analytical Chemistry, vol. 86, pp. 206-221, 2017.

[4] S. Čejková, I. Králová-Lesná, and R. Poledne, "Monocyte adhesion to the endothelium is an initial stage of atherosclerosis development," Cor et Vasa, vol. 58, no. 4, pp. e419-e425, 2016.

[5] I. M. Fenyo and A. V. Gafencu, "The involvement of the monocytes/macrophages in chronic inflammation associated with atherosclerosis," Immunobiology, vol. 218, no. 11, pp. 1376-1384, 2013.

[6] D. A. Chistiakov, A. N. Orekhov, and Y. V. Bobryshev, "Immune-inflammatory responses in atherosclerosis: role of an adaptive immunity mainly driven by $\mathrm{T}$ and $\mathrm{B}$ cells," Immunobiology, vol. 221, no. 9, pp. 1014-1033, 2016.

[7] E. J. Moticka, "Chapter 1-innate host defense mechanisms and adaptive immune responses," in A Historical Perspective on Evidence-Based Immunology, pp. 1-8, Elsevier, Amsterdam, Netherlands, 2016.

[8] J. R. Scalea, J. Bromberg, S. T. Bartlett, and T. M. Scalea, "Mechanistic similarities between trauma, atherosclerosis, and other inflammatory processes," Journal of Critical Care, vol. 30, no. 6, pp. 1344-1348, 2015.

[9] W. Xianli and G. S. Alexander, "Mitigation of inflammation with foods," Journal of Agricultural and Food Chemistry, vol. 60 , no. 27 , pp. 6703-6717, 2012.

[10] H. Jiang, L. Yang, G.-X. Ma et al., "New phenylpropanoid derivatives from the fruits of Xanthium sibiricum and their antiinflammatory activity," Fitoterapia, vol. 117, pp. 11-15, 2017.

[11] V. S. Honmore, A. D. Kandhare, P. P. Kadam et al., "Isolates of Alpinia officinarum Hance as COX-2 inhibitors: evidence from anti-inflammatory, antioxidant and molecular docking studies," International Immunopharmacology, vol. 33, pp. 8-17, 2016.

[12] I. A. Ahmed, M. A. Mikail, M. bin Ibrahim et al., "Antioxidant activity and phenolic profile of various morphological parts of underutilised Baccaurea angulata fruit," Food Chemistry, vol. 172, pp. 778-787, 2015.

[13] I. A. Ahmed, M. A. Mikail, and M. Ibrahim, "Baccaurea angulata fruit juice ameliorates altered hematological and biochemical biomarkers in diet-induced hypercholesterolemic rabbits,” Nutrition Research, vol. 42, pp. 31-42, 2017.

[14] M. Ibrahim, M. A. Mikail, I. A. Ahmed et al., "Comparison of the effects of three different Baccaurea angulata whole fruit juice doses on plasma, aorta and liver MDA levels, antioxidant enzymes and total antioxidant capacity," European Journal of Nutrition, vol. 57, no. 5, pp. 1817-1878, 2017.

[15] I. A. Ahmed, M. A. Mikail, and M. Ibrahim, "Baccaurea angulata fruit juice protects rabbit's liver from 
hypercholesterolemia-induced injury," Malaysian Journal of Medical Research, vol. 1, no. 4, pp. 18-21, 2017.

[16] M. A. Mikail, I. A. Ahmed, M. Ibrahim et al., "Baccaurea angulata fruit inhibits lipid peroxidation and induces the increase in antioxidant enzyme activities," European Journal of Nutrition, vol. 55, no. 4, pp. 1435-1444, 2016.

[17] M. Ibrahim, I. A. Ahmed, M. A. Mikail et al., "Baccaurea angulata fruit juice reduces atherosclerotic lesions in dietinduced hypercholesterolemic rabbits," Lipids in Health and Disease, vol. 16, no. 1, pp. 1-8, 2017.

[18] M. S. Karbiner, L. Sierra, C. Minahk, M. C. Fonio, M. P. D. Bruno, and S. Jerez, "The role of oxidative stress in alterations of hematological parameters and inflammatory markers induced by early hypercholesterolemia," Life Sciences, vol. 93, no. 15, pp. 503-508, 2013.

[19] N. R. Hadi, F. A. Rezeg, F. Al-Amran, and M. A. A. Hussein, "Evaluation of the effects of glimepiride (Amaryl) and repaglinide (novoNorm) on atherosclerosis progression in high cholesterol-fed male rabbits," Journal of Cardiovascular Disease Research, vol. 3, no. 1, pp. 5-11, 2012.

[20] F. Merhi-Soussi, B. R. Kwak, D. Magne et al., "Interleukin-1 plays a major role in vascular inflammation and atherosclerosis in male apolipoprotein E-knockout mice," Cardiovascular Research, vol. 66, no. 3, pp. 583-593, 2005.

[21] T. Benn, B. Kim, Y.-K. Park et al., "Polyphenol-rich blackcurrant extract prevents inflammation in diet-induced obese mice," Journal of Nutritional Biochemistry, vol. 25, no. 10, pp. 1019-1025, 2014.

[22] J. Chen, C. Y. Du, K. Y. Lam et al., "The standardized extract of Ziziphus jujuba fruit (Jujube) regulates pro-inflammatory cytokine expression in cultured murine macrophages: suppression of lipopolysaccharide-stimulated NF- $\mathrm{B}$ activity," Phytotherapy Research, vol. 28, no. 10, pp. 1527-1532, 2014.

[23] T. Dietrich, T. Hucko, C. Schneemann et al., "Local delivery of IL-2 reduces atherosclerosis via expansion of regulatory T cells," Atherosclerosis, vol. 220, no. 2, pp. 329-336, 2012.

[24] E. Johnson, D. Førland, L. Saetre, S. Bernardshaw, T. Lyberg, and G. Hetland, "Effect of an extract based on the medicinal mushroom Agaricus blazei murill on release of cytokines, chemokines and leukocyte growth factors in human blood ex vivo and in vivo," Scandinavian Journal of Immunology, vol. 69, no. 3, pp. 242-250, 2009.

[25] S. Jung, M.-S. Lee, Y. Shin et al., "Anti-obesity and antiinflammatory effects of high hydrostatic pressure extracts of ginseng in high-fat diet induced obese rats," Journal of Functional Foods, vol. 10, pp. 169-177, 2014.

[26] C. Xie, J. Kanga, R. Burris et al., "Acaí juice attenuates atherosclerosis in ApoE deficient mice through antioxidant and anti-inflammatory activities," Atherosclerosis, vol. 216, no. 2, pp. 327-333, 2011.

[27] A. Y. Odendaal, A. G. Schauss, R. Watson, V. Reedy, and S. Zibadi, "Potent antioxidant and anti-inflammatory flavonoids in the nutrient-rich Amazonian palm fruit, Aça1 (Euterpe spp.)," in Polyphenols in Human Health and Disease, pp. 219-239, Elsevier, Amsterdam, Netherlands, 2014.

[28] R. Li, A. Paul, K. W. Ko et al., "Interleukin-7 induces recruitment of monocytes/macrophages to endothelium," European Heart Journal, vol. 33, no. 24, pp. 3114-3123, 2011.

[29] S. Apostolakis, K. Vogiatzi, V. Amanatidou, and D. A. Spandidos, "Interleukin 8 and cardiovascular disease," Cardiovascular Research, vol. 84, no. 3, pp. 353-360, 2009.

[30] J. Zhang, R. Liang, L. Wang et al., "Effects of an aqueous extract of Crataegus pinnatifida Bge. var. major NE Br. fruit on experimental atherosclerosis in rats," Journal of Ethnopharmacology, vol. 148, no. 2, pp. 563-569, 2013.

[31] Z. Mallat, A. Corbaz, A. Scoazec et al., "Expression of interleukin-18 in human atherosclerotic plaques and relation to plaque instability," Circulation, vol. 104, no. 14, pp. 1598-1603, 2001.

[32] R. Elhage, J. Jawien, M. Rudling et al., "Reduced atherosclerosis in interleukin-18 deficient apolipoprotein E-knockout mice," Cardiovascular Research, vol. 59, no. 1, pp. 234-240, 2003.

[33] K. Kitagawa, M. Matsumoto, T. Sasaki et al., "Involvement of ICAM-1 in the progression of atherosclerosis in APOEknockout mice," Atherosclerosis, vol. 160, no. 2, pp. 305310, 2002.

[34] M.-C. Bourdillon, R. N. Poston, C. Covacho, E. Chignier, G. Bricca, and J. L. McGregor, "ICAM-1 deficiency reduces atherosclerotic lesions in double-knockout mice (ApoE-/ -/ICAM-1-/-) fed a fat or a chow diet," Arteriosclerosis, Thrombosis, and Vascular Biology, vol. 20, no. 12, pp. 2630-2635, 2000.

[35] A. A. Amran, Z. Zakaria, F. Othman, S. Das, H. M. AlMekhlafi, and N.-A. M. Nordin, "Changes in the vascular cell adhesion molecule-1, intercellular adhesion molecule-1 and c-reactive protein following administration of aqueous extract of piper sarmentosum on experimental rabbits fed with cholesterol diet," Lipids in Health and Disease, vol. 10, no. 1, p. 2, 2011.

[36] L. Lind, "Circulating markers of inflammation and atherosclerosis," Atherosclerosis, vol. 169, no. 2, pp. 203-214, 2003.

[37] Y.-1. Chang, C.-1. Chen, C.-L. Kuo, B.-c. Chen, and J.-s. You, "Glycyrrhetinic acid inhibits ICAM-1 expression via blocking JNK and NF- $\kappa B$ pathways in TNF- $\alpha$-activated endothelial cells," Acta Pharmacologica Sinica, vol. 31, no. 5, pp. 546-553, 2010.

[38] M. A. Piranfar, "The correlation between high-sensitivity C-reactive protein (hsCRP) serum levels and severity of coronary atherosclerosis," International Cardiovascular Research Journal, vol. 8, no. 1, p. 6, 2014.

[39] P. R. N. Viecili, D. O. Borges, K. Kirsten et al., "Effects of Campomanesia xanthocarpa on inflammatory processes, oxidative stress, endothelial dysfunction and lipid biomarkers in hypercholesterolemic individuals," Atherosclerosis, vol. 234, no. 1, pp. 85-92, 2014.

[40] T. W. Hein, U. Singh, J. Vasquez-Vivar, S. Devaraj, L. Kuo, and I. Jialal, "Human C-reactive protein induces endothelial dysfunction and uncoupling of eNOS in vivo," Atherosclerosis, vol. 206, no. 1, pp. 61-68, 2009.

[41] M. Canault, F. Peiretti, F. Kopp et al., "The TNF alpha converting enzyme (TACE/ADAM17) is expressed in the atherosclerotic lesions of apolipoprotein E-deficient mice: possible contribution to elevated plasma levels of soluble TNF alpha receptors," Atherosclerosis, vol. 187, no. 1, pp. 82-91, 2006.

[42] M. F. Nageh, E. T. Sandberg, K. R. Marotti et al., "Deficiency of inflammatory cell adhesion molecules protects against atherosclerosis in mice," Arteriosclerosis, Thrombosis, and Vascular Biology, vol. 17, no. 8, pp. 1517-1520, 1997.

[43] R. Fei, Y. Fei, and S. Zheng, "Purified polysaccharide from Ginkgo biloba leaves inhibits P-selectin-mediated leucocyte adhesion and inflammation," Acta Pharmacologica Sinica, vol. 29, no. 4, pp. 499-506, 2008. 


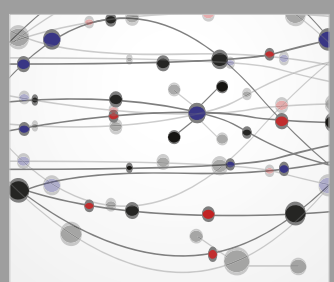

The Scientific World Journal
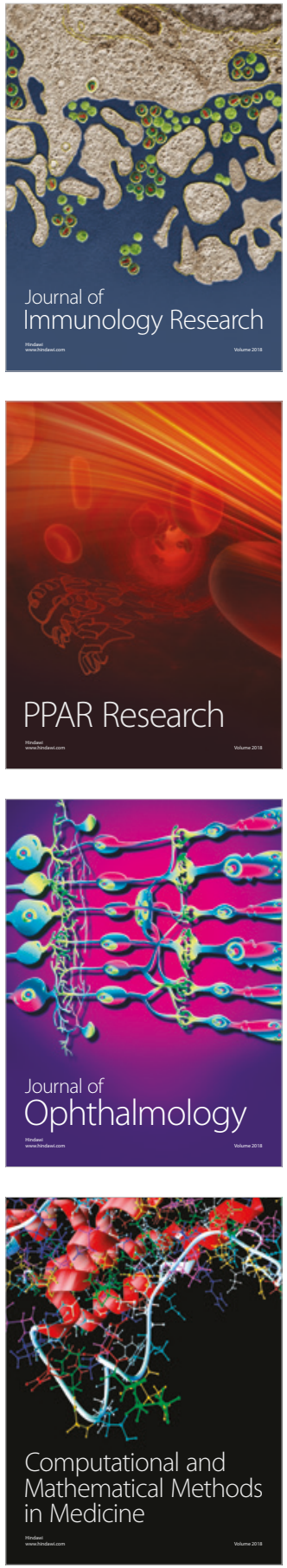

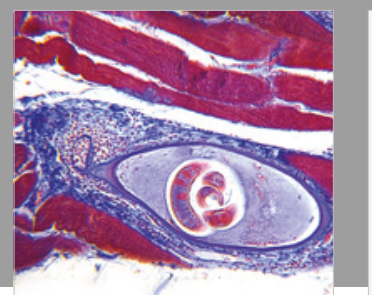

Gastroenterology Research and Practice

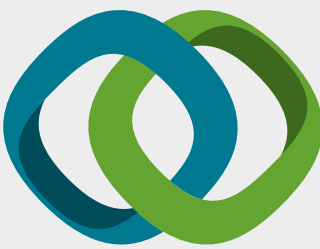

\section{Hindawi}

Submit your manuscripts at

www.hindawi.com
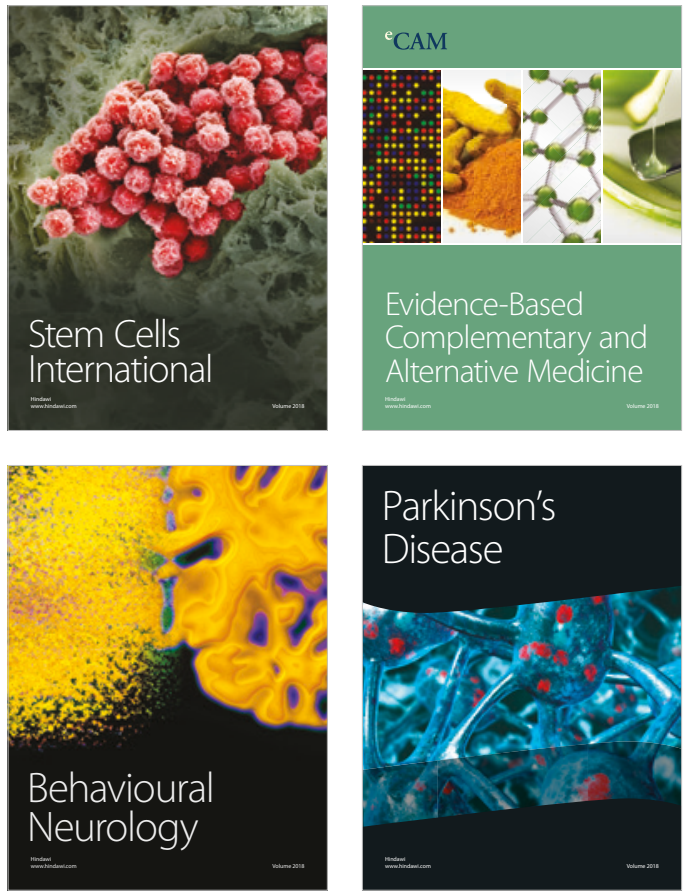

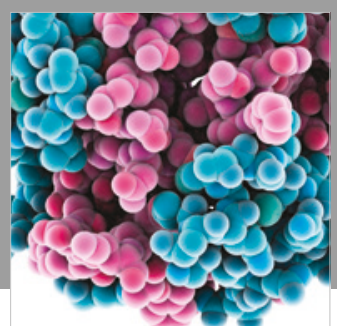

ournal of

Diabetes Research

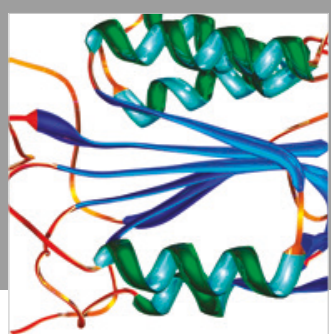

Disease Markers
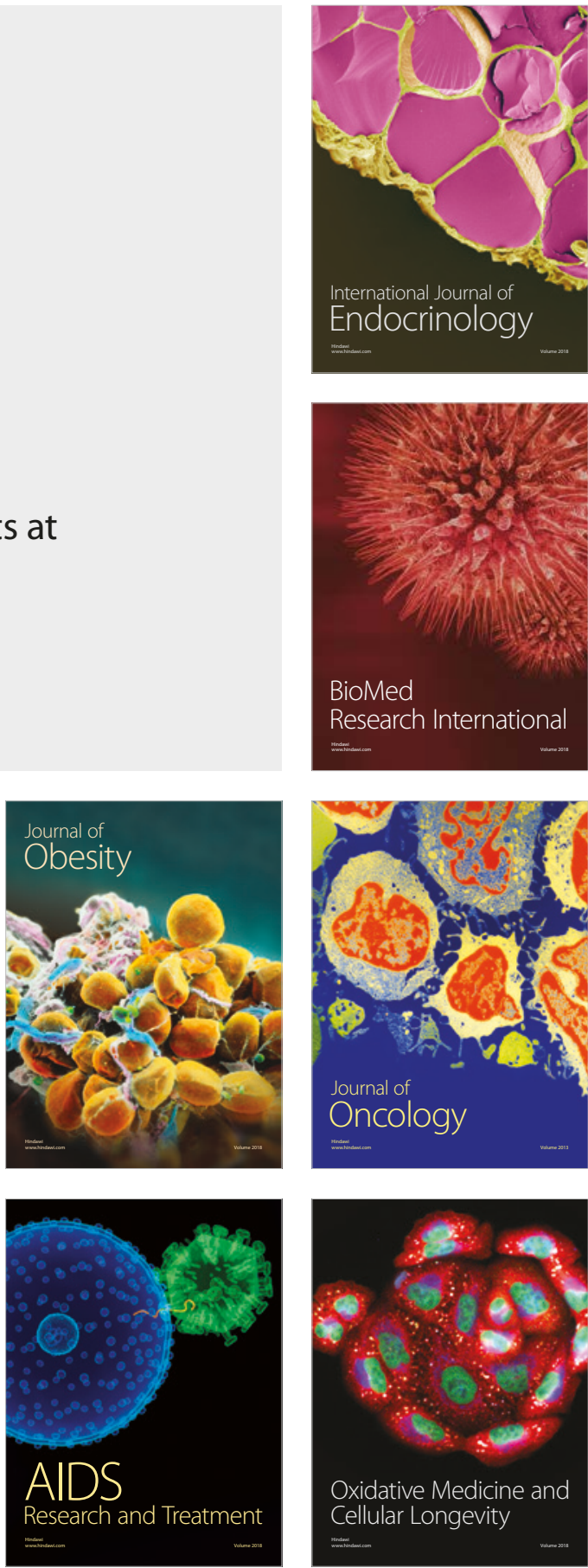